\title{
ESTÁDIO DE MATURAÇÃO E QUALIDADE DE SEMENTES DE GIRASSOL ( ${ }^{1}$ )
}

\author{
JOCELY ANDREUCCETTI MAEDA $\left({ }^{2}\right)$, MARIA REGINA GONÇALVES UNGARO $(3,4)$, \\ ANTONIO AUGUSTO DO LAGO $(2,4)$ e LUIZ FERNANDES RAZERA $(2,4)$
}

\begin{abstract}
RESUMO
Componentes da qualidade de sementes de girassol do cultivar IAC-Anhandy foram avaliados nos anos agricolas de 1983/84 (Campinas, SP) e 1984/85 (Tatui, SP). Amostras foram coletadas das regiōes central, intermediária e periférica de capftulos colhidos aos 10,20,30 e 40 dias após florescimento. Em 1983/84, a proporção de sementes chochas aos 10 dias foi bastante elevada, variando entre 64,1 e $\overline{94}, 4 \%$. Com o avanço da maturação, a porcentagem de sementes chochas decresceu drasticamente, baixando, aos 40 dias, para 5,2, 2,2 e 2,6 nas regiōes central, intermediária e periférica respectivamente. Os teores de b́leo na semente aos 10 dias foram muito baixos (entre 2,2 e 2,6\%), mas aumentaram consideravelmente até os 30 dias, quando atingiram valores entre 44,8 e $46,6 \%$, permanecendo praticamente estáveis até os $\mathbf{4 0}$ dias. A viabilidade das sementes (porcentagem de germinação + porcentagem de dormência) exibiu indices relativamente baixos aos 10 dias, aumentando sensivelmente até 30 dias, quando atingiram valores próximos de $100 \%$, com uma proporção de sementes dormentes acima de $90 \%$; aos 20,30 e 40 dias, não foram verificadas diferenças de germinação e dormência entre regiōes do capítulo. Aos seis meses de armazenamento, a dormência tornou-se nula em todos os trata-
\end{abstract}

( $\left.{ }^{1}\right)$ Recebido para publicação em 15 de julho de 1986.

( ${ }^{2}$ ) Seçäo de Sementes, Instituto Agronómico (IAC), Caixa Postal 28, 13001 Campinas (SP).

(3) Seção de Oleaginosas, IAC.

$\left({ }^{4}\right)$ Com bolsa de suplementação do CNPq. 
mentos. O material colhido aos 10 dias deteriorou-se rapidamente, nāo exibindo germinação aos 12 meses. As sementes colhidas aos 20,30 e 40 dias, independente da regiâo do capftulo, conservaram-se bem, mantendo indices de germinação acima de $80 \%$ até 24 meses de armazenamento. Tendências semelhantes foram observadas no ano agrícola 1984/85, quanto a germinação, dormência e sementes chochas, tendo estas últimas, após 20 dias do florescimento, apresentado valores mais altos que no ano anterior, provavelmente devido às condiçōes ácidas do solo.

Termos de indexação: girassol, Helianthus annuus L., sementes; maturaçăo, qualidade; armazenamento.

\section{INTRODUÇÃO}

Um dos aspectos interessantes da qualidade de sementes é a dormência, que as impede de germinar pronta e uniformemente após plantio no campo. Dentro de uma mesma espécie, a dormência pode estar associada ao cultivar (fator genético) e sofrer também forte influência do estádio de maturaçāo das sementes (ROBERTS, 1972; THOMSON, 1979).

Amostras de sementes (aquênios) de girassol do cultivar IAC-Anhandy submetidas ao teste-padrão de germinação têm mostrado graus variáveis de dormência, notadamente quando recém-colhidas. Essa dormência causa problemas na avaliação da sua qualidade fisiológica, lançando dúvidas sobre seu uso imediato para fins de semeadura no campo.

ZIMMERMAN \& ZIMMER (1978), estudando épocas de colheita dos cultivares de girassol Peredovik e Sputnik, observaram que as sementes colhidas em estádio de desenvolvimento mais avançado tinham um periodo de dormência mais curto que aquelas colhidas mais precocemente. KOLE \& GUPTA (1982) verificaram que nas variedades Modem (anã) e EC-68414 (alta) de girassol, a maturidade fisiológica foi atingida entre 30 e 36 dias após o florescimento, quando apresentaram máximo aumento em peso seco; aos 36 dias, sua germinação foi 89 e $86 \%$ respectivamente. Flint Jr., citado por BITTENCOURT (1984), estudando a maturação do 'Peredovik', concluiu que a matéria seca, a porcentagem de germinação e o teor de óleo aumentaram até 40 dias após o florescimento, quando foi alcançada a maturidade fisiológica. BITTENCOURT (1984), trabalhando com os cultivares IAC-Anhandy e Contisol (híbrido), verificou que a maturidade fisiológica das sementes ocorreu entre 39 e 42 dias após o florescimento para o primeiro e entre 40 e 26 dias para o segundo. Conforme esse autor, para a obtenção de sementes com alta capacidade germinativa e vigor, a colheita poderia ser realizada aos 100-105 dias após o plantio para o 'IAC-Anhandy' e aos 110-115 dias para o 'Contisol'.

Colheita precoce pode refletir excessiva quantidade de sementes imaturas, malformadas e chochas, com conseqüente diminuição do rendimento por área, grande descarte no beneficiamento e baixo vigor das sementes. 
SALVADOR (1948) notou que na variedade Kruglik, o material colhido aos 83 dias após plantio continha $71,08 \%$ de sementes chochas, contra apenas $2,82 \%$ aos 117 dias.

O teor de óleo na semente de girassol parece estar fortemente relacionado com sua maturidade fisiológica (ROBERTSON et al., 1978; KOLE \& GUPTA, 1982; BITTENCOURT, 1984). ROBERTSON et al. (1978) definiram o ponto de maturidade fisiológica para o girassol híbrido 'Sun Gro 380 ' como o período de 35 dias após o florescimento, quando as sementes atingiram o máximo de teor de óleo e de matéria seca.

A velocidade de deterioração das sementes durante o armazenamento é também influenciada pelo seu estádio de maturação; sementes imaturas perdem mais rapidamente a viabilidade do que as completamente maduras (DELOUCHE \& BASKIN, 1973; JUSTICE \& BASS, 1978).

O estádio de maturação das sementes de girassol necessita especificamente ser bem definido, pois numa mesma época podem ocorrer diferenças em grau de maturação entre capítulos de diferentes plantas; essa diferença é maior quando do plantio de variedades em vez de híbridos. Além disso, como um capitulo individual floresce por aproximadamente uma semana, as sementes localizadas em diferentes regiōes do capitulo podem diferir em maturidade fisiológica (ZIMMERMAN \& ZIMMER, 1978), o que tem sido demonstrado com relação a teor de óleo (ZIMMERMAN \& FICK, 1973; MATTHES \& UNGARO, 1983). É provável que o mesmo também ocorra com relação a outros fatores de qualidade, como germinação, dormência e proporção de sementes chochas.

O objetivo do presente trabalho foi avaliar diversos aspectos da qualidade de sementes de girassol do 'AC-Anhandy', provenientes de três regiōes de capitulos que foram colhidos em diferentes periodos após o florescimento, produzidos em dois anos agrícolas.

\section{MATERIAL E MÉTODOS}

Foram estudadas as sementes do 'IAC-Anhandy', de ciclo médio a curto (100-110 dias), produzidas em dois anos agricolas, cada um em uma região, ou seja, em 1983/84, no Centro Experimental de Campinas, e em 1984/85 na Estação Experimental de Tatuí, ambos do Instituto Agronômico.

Nas duas safras, preparo do solo, adubação, semeadura e tratos culturais foram realizados na forma usualmente recomendada para a cultura. No florescimento, os capitulos foram vistoriados, sendo 80 deles escolhidos ao acaso, etiquetados quando se encontravam na fase de $2 / 3$ do florescimento (antese em $2 / 3$ das flores) e cobertos com saco plástico trançado com o único objetivo de evitar o ataque de pássaros. A cada dez dias, até 40 dias após o florescimento, vinte dos capitulos anteriormente etiquetados foram colhidos e, no laboratório, secos a $30^{\circ} \mathrm{C}$ em secador com ventilação forçada de ar até que as sementes pudessem ser facilmente destacadas dos capítulos. A retirada das sementes foi 
manual e feita separadamente de três regiōes distintas dos capitulos, correspondentes a três faixas concêntricas de áreas semelhantes, a saber. central, intermediária e periférica. Após isso, as sementes foram mantidas em condições ambientes para uniformizaçâo da umidade, que foi determinada pelo método da estufa a $105^{\circ} \mathrm{C}$ por 24 horas (BRASIL, 1980), verificando-se um teor ao redor de $8,0 \%$ (base úmida) em todos os tratamentos.

Efetuaram-se avaliações de sementes chochas, de teor de óleo e de germinaçāo e dormência. A porcentagem, em peso, de sementes chochas (sementes sem embrião) foi determinada com auxilio do ventilador vertical de laboratório tipo "South Dakota", ajustado, após obsenvaçōes preliminares, na abertura $n^{\circ}$ 30. A avaliação do teor de óleo foi feita apenas na safra $83 / 84$, na fração "pesada" (porção remanescente após ventilação, formada por sementes com embriāo em cada um dos estádios de desenvolvimento), através do processo de ressonância nuclear magnética (RNM), realizando-se dez determinaçōes por amostra (SCHAEFER \& STEJSKAL, 1976).

Realizaram-se os testes de germinação, com observaçōes concomitantes de sementes dormentes, com quatro repetiçōes de 50 sementes cada uma,

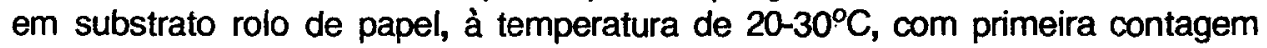
aos três e a última aos sete dias após o início dos testes (BRASIL, 1980).

Depois dos testes iniciais, armazenaram-se as sementes em condiçöes não controladas de laboratório, realizando-se testes posteriores, apenas de germinação, aos 6, 12 e 24 meses na safra 1983/84 e aos 12 meses na safra 1984/85. Em determinados periodos, alguns testes não foram executados no material colhido aos dez dias, devido à escassez de sementes.

Os dados de germinação e dormência foram analisados estatisticamente segundo esquema inteiramente casualizado, com quatro repetiçöes, sendo a comparação de médias feita pelo teste de Tukey a $5 \%$ de probabilidade.

\section{RESULTADOS E DISCUSSÃO}

As porcentagens de sementes chochas, óleo, germinação e dormência das sementes produzidas na safra 1983/84 encontram-se no quadro 1. A quantidade de sementes chochas no material colhido aos 10 dias apos o florescimento foi bastante elevada, notadamente nas regiōes central e intermediária, com 99,4 e $92,0 \%$ respectivamente. Refletindo o grau de maturação das sementes, a porcentagem de sementes chochas diminuiu sensivelmente com o número de dias após a floraçāo e do centro para a periferia do capltulo, tendo baixado, aos 40 dias, para 5,2,2,2 e 2,6\% respectivamente nas regiōes central, intermediária e periférica. Estes últimos dados são semelhantes aos de SALVADOR (1948), que encontrou $2,82 \%$ de sementes chochas, considerando o capítulo todo, na maturação da variedade Kruglik. 
ESTADIO DE MATURAÇĀO EM GIRASSOL

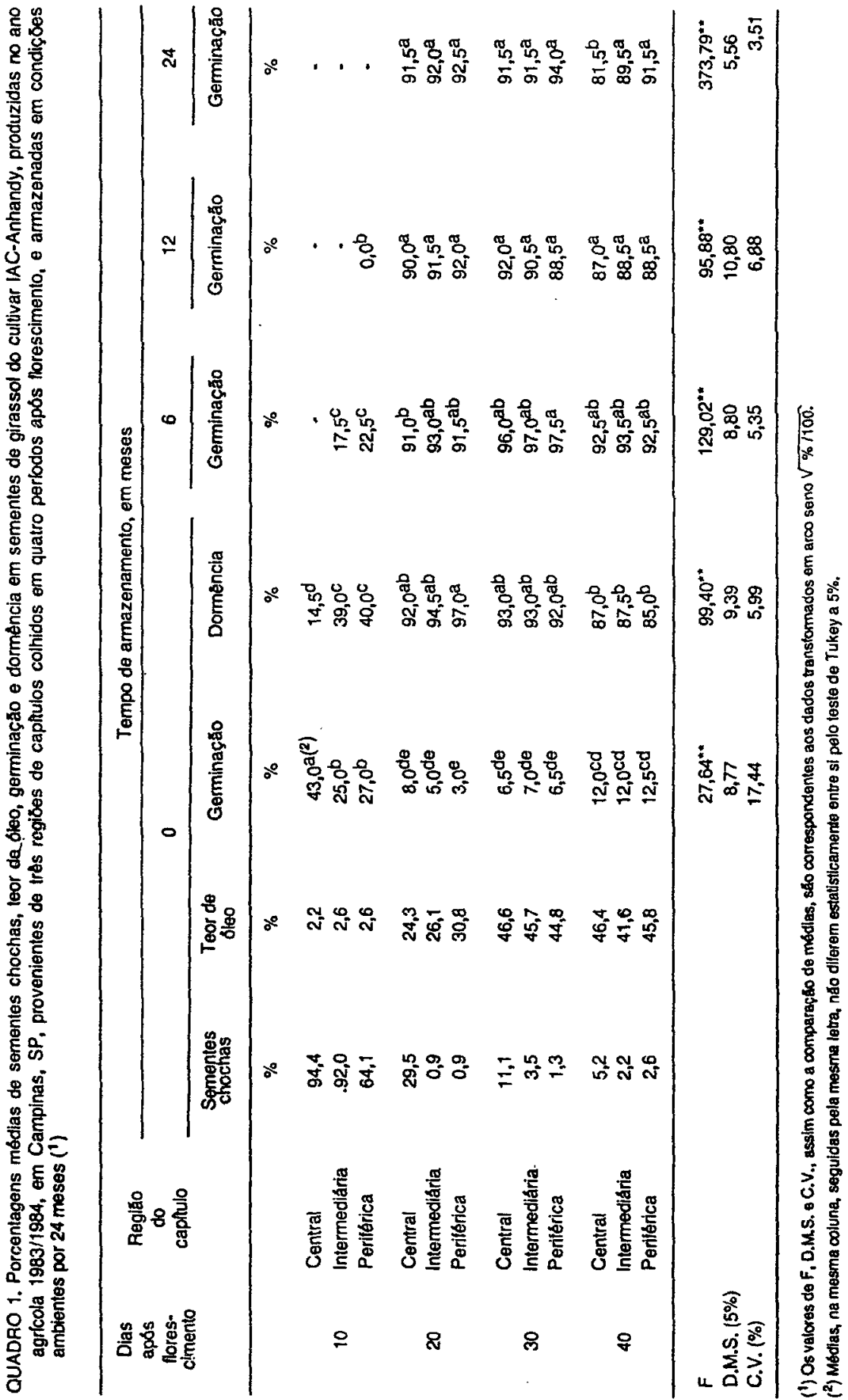


O teor de óleo foi muito baixo aos dez dias do florescimento, apresentando no centro um valor inferior $(2,2 \%)$ ao das outras duas regiōes do capítulo $(2,6 \%)$. Valores similares foram relatados por DORRELL (1978) nos cultivares Krasnodarets $(2,6 \%)$ e Peredovik $(2,1 \%)$, porém, cinco dias após o florescimento. ROBERTSON et al. (1978) encontraram, no hibrido Sun Gro, teor de óleo um pouco menor que os verificados por DORRELL (1978) após sete dias do florescimento. $O$ teor de óleo aumentou consideravelmente dos 10 aos 30 dias, quando foram atingidos valores entre 44,8 e $46,6 \%$, permanecendo praticamente estáveis até os 40 dias. Esses teores são normais para as semente do 'IAC-Anhandy' (BITTENCOURT, 1984). Para O 'EC 68415', LAKSHMINARAYANA et al. (1980) encontraram, aos 30 e 40 dias, porcentagens de, respectivamente, 42 e $43 \%$. Não se verificaram diferenças sensiveis entre sementes colhidas aos 30 e 40 dias, nas diferentes regiōes do capitulo. Esse fato pode ser importante para a escolha do momento da colheita, sem prejuizo no teor de óleo.

Embora as diferenças maiores quanto a teor de óleo de sementes de girassol sejam verificadas entre épocas de colheita, podem ocorrer algumas variaçōes dentro de épocas semelhantes, devido, principalmente, a fatores genéticos (cultivares) e condiçōes ambientes durante a fase de maturação.

As porcentagens de germinação das sementes colhidas aos dez dias (entre 25,0 e 43,0) foram superiores às daquelas em periodos posteriores, e as porcentagens de dormência foram relativamente baixas, conduzindo a valores de viabilidade (porcentagem de germinação + porcentagem de dormência) muito inferiores às das outras colheitas. Essa baixa viabilidade se deve ao estádio incipiente de formação das sementes no referido período. Aos 20 e 30 dias, ocorreu um decréscimo na germinação, que variou de 3,0 a $8,0 \%$ e de 6,5 a $7,0 \%$ respectivamente; no entanto, houve um aumento considerável na proporção de sementes dormentes, com valores acima de $90 \%$ nas três regiöes do capítulo, revelando indices de viabilidade próximos de $100 \%$. Nesses dois periodos KOLE \& GUPTA (1982) encontraram, na variedade Modern, $83 \%$ de germinação nas sementes coIhidas 30 dias após o florescimento, enquanto BITTENCOURT (1984) verificou, no mesmo periodo, $41,25 \%$ para o 'IAC-Anhandy'. SALVADOR (1948) relatou valores de germinação acima de $90 \%$ dos 102 aos 144 dias após plantio, no 'Gray Striped'. Em geral, a literatura consultada não relata dormência em sementes de girassol; embora tal inexistência possa ser devida à constituição genética do cultivar, casos existem em que a sua não detecção pode ser causada por um ou mais dos seguintes fatores: (a) após a colheita, as sementes são armazenadas por determinado tempo antes de serem testadas, como o fizeram KOLE \& GUPTA (1982) e BITTENCOURT (1984), o que pode ter conduzido à perda da dormência, como foi verificado no 'IAC-Anhandy' por MAEDA \& UNGARO (1985); (b) nos testes de germinação, utiliza-se terra (SALVADOR, 1948) ou areia como substrato (BITTENCOURT, 1984), sendo contadas e mencionadas apenas as plântulas 
emergidas; (c) a duração excessiva do teste de emergência (SALVADOR, 1948) pode possibilitar a quebra de dormência das sementes, que, num periodo mais breve, permaneceriam em estado dormente no substrato.

A menor porcentagem de dormência, aos 40 dias, quando comparada com a ocorrida aos 20 e 30 dias, parece indicar tendência de sua diminuiçăo após maturação no campo, antes da colheita.

Com exceção do período de dez dias, não se observaram diferenças estatisticas de germinação e dormência entre regiōes do capítulo.

Aos seis meses de armazenamento, a dormência tornou-se nula em todos os tratamentos, confirmando relato de MAEDA \& UNGARO (1985) e observações $\epsilon m$ testes de rotina realizados em laboratório por ocasiáo da época normal de plantio no campo, após perlodo semelhante de armazenamento. O material colhido aos dez dias, ainda em grau incipiente de maturação, deteriorou-se rapidamente, exibindo germinação nula aos doze meses. As sementes colhidas aos 20,30 e 40 dias, independente de região do capítulo, conservaram-se bem e de forma semelhante entre si, mantendo índices de germinação acima de $80 \%$ até 24 meses.

No quadro 2 encontram-se os resultados das determinaçōes de sementes chochas, germinação e dormência, realizadas na safra 1984/85. Tendências semelhantes às de 1983/84 foram verificadas nesse ano agricola. Em todos os períodos, a proporção de sementes chochas refletiu claramente as diferenças de grau de maturação entre épocas de colheita e, mais notadamente, entre regiōes do capítulo; como exemplo, aos dez dias, os indices de sementes chochas nas regiōes central, intermediária e periférica foram de 92,2, 80,4 e $63,0 \%$ respectivamente. Com exceção do período de dez dias, em todos os outros, as porcentagens de sementes chochas foram sensivelmente superiores àquelas de 1983/84; isso foi devido, provavelmente, às condiçöes de acidez do solo $(\mathrm{pH}=5,1)$ em que foi conduzido o experimento.

Os valores de viabilidade das sementes colhidas aos dez dias foram bastante baixos, próximos de $0 \%$ nas regiōes central e intermediária, em estádio mais imaturo. Essas porcentagens aumentaram significativamente dos 10 as 20 dias e permaneceram altas e relativamente constantes até os $\mathbf{4 0}$ dias. Como na safra anterior, os indices de dormência foram bastante altos, mesmo aos 40 dias após florescimento, quando variaram de 82,5 a $84,0 \%$.

Aos doze meses de armazenamento, a dormência reduziurse a $0 \% \mathrm{em}$ todos os tratamentos. Nesse mesmo periodo, as sementes colhidas aos dez dias exibiram baixas porcentagens de germinação, enquanto aquelas colhidas aos 20 , 30 e 40 dias conservaram-se bem, mantendo valores altos, acima de $90 \%$, independente da região do capltulo, da mesma forma que na safra anterior. 


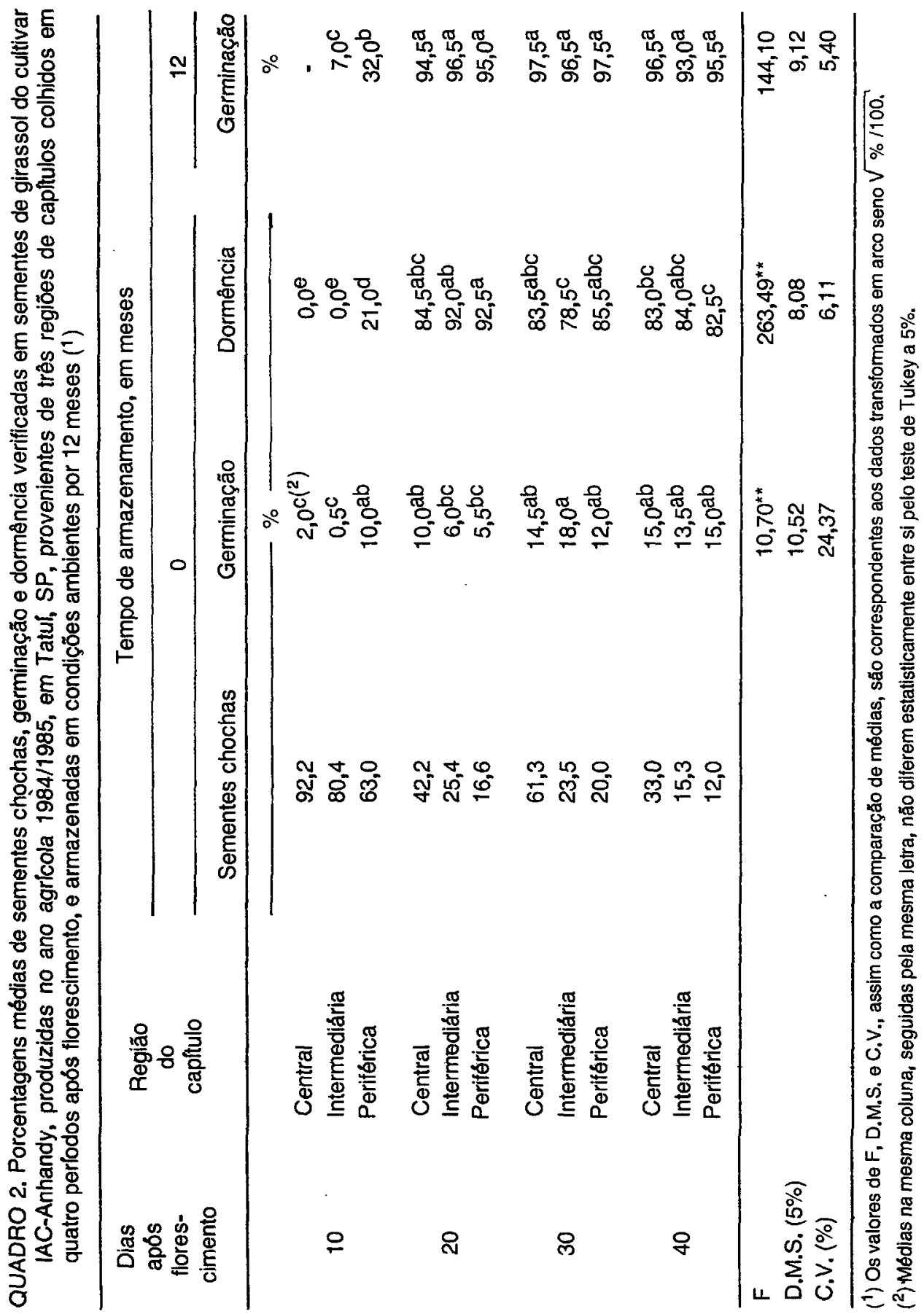




\section{CONCLUSÕES}

1) As sementes de girassol do cultivar IAC-Anhandy atingiram plena maturação entre 30 e 40 dias após o florescimento, quando apresentaram os menores índices de sementes chochas e os maiores valores de viabilidade e teor de oleo.

2) A viabilidade (porcentagem de germinação + porcentagem de dormência) e o teor de óleo não dependeram da localização da semente no capítulo quando se efetuou a colheita, decorridos 20 e 30 dias respectivamente do florescimento.

3) Os altos índices de dormência na completa maturação das sementes tornaram-se nulos aos seis meses de armazenamento.

4) As sementes colhidas com alta viabilidade conservaram-se muito bem, exibindo altos índices de germinação, até os 24 meses de armazenamento.

\section{SUMMARY}

\section{MATURATION AND QUALITY OF SUNFLOWER SEEDS}

Several components of sunflower (Helianthus annuus L.) seed quality were evaluated during the $1983 / 84$ and $84 / 85$ crop years, at two Experimental Stations of the Instituto Agronômico, São Paulo, Brazil. Seeds of the 'IAC-Anhandy' were collected from the central, middle and external parts of the heads, harvested at 10,20, 30 and 40 days after flowering (D.A.F.). The percentage of empty seeds was high in the samples harvested at 10 D.A.F. but it decreased sharply as seed maturity progressed, with values as low as 5.2,2.2 and $2.6 \%$ for the central, middle and external parts of the heads at 40 D.A.F. The seed oil content varied markedly from $2.2 \%$ at 10 D.A.F. to the maximum of $46.6 \%$ at 30 D.A.F. Also, the seed viability indices ( $\%$ germination + \% dormancy) were maximum at 30 D.A.F. with values close to $100 \%$ and seed dormancy above $90 \%$. Differences in seed germination and dormancy among the sunflower head parts (central, middle and external) were not observed at 20,30 and 40 D.A.F. After six months of storage under noncontrolied conditions, seed dormancy was released in all treatments. Nevertheless, under these conditions, samples harvested at 10 D.A.F. were completely deteriorated after 12 months and those harvested at 20,30 and 40 D.A.F. remained well preserved showing germination indices as high as $80 \%$ even after 24 months of storage.

Index terms: sunflower, Helianthus annuus L; seeds; maturation; quality; storage. 


\section{REFERÊNCIAS BIBLIOGRÁFICAS}

BITTENCOURT, J.F.N. Maturação de sementes de girassol (Helianthus annuus L.). Jaboticabal, UNESP, 1984. 97p. Tese (Mestrado)

BRASIL. Ministério da Agricultura. Divisão de Sementes e Mudas. Regras para anålise de sementes Braslia, 1980. 188p.

DELOUCHE, J.C. \& BASKIN, C.C. Accelerated aging techniques for predicting the relative storability of seed lots. Seed Science \& Technology, 1:427-452, 1973.

DORRELL, D.G. Concentrations of chlorogenic acid, oil, fatty acids in developing sunflower seeds. Crop Science, 18:667-670, 1978.

JUSTICE, O.L. \& BASS, L.N. Principles and practices of seed storage. Washington, U.S.D.A., 1978. 289p. (Agriculture Handbook, 506)

KOLE, S. \& GUPTA, K. The timing of physiological maturity of seeds of sunflower: evaluation through multiple tests. Seed Science \& Technology, 10:457-467, 1982.

LAKSHMINARAYANA, M.R.; SEETHATAM, A.; RAMANATHAN, K.V. \& KHETRAPAL, C.L. NMR study of the oil build-up in sunflower seeds. Current Science, 49(8):308-309, 1980.

MAEDA, J.A. \& UNGARO, M.R.G. Study of sunflower "seed" dormancy. In: INTERNATIONAL SUNFLOWER CONFERENCE, 11., Mar del Plata, Argentina, 1985. p.73-79.

MATTHES, L.A.F. \& UNGARO, M.R.G. Influência da localização da semente na porcentagem de óleo e no teor de umidade em capftulos de girassol. Bragantia, Campinas, 42:239-244, 1983. (Nota, 2)

ROBERTS, E.H. Dormancy: a factor affecting seed survival in the soil. In:ROBERTS, E.H., ed. Viability of seeds. Syracuse, University Press, 1972. p.321-359.

ROBERTSON, J.A.; CHAPMAN, G.W. \& WILSON JR., R.L. Relation of days after flowering to chemical composition and physiological maturity of sunflower seed. Journal of the American Oil Chemists Society, 55(2):266-269, 1978.

SALVADOR, V.G. Estudio del processo de madurez del girasol y la determinación de la mejor época para cosecharlo. Agricultura Tecnica, Chile, 8(2):112-130, 1948.

SCHAEFER, J. \& STEJSKAL, E.O. Carbon-13 nuciear magnetic resonance analysis of intact oil seeds. Journal of the American Oil Chemists Society, 53:366-369, 1976.

THOMSON, J.R. An introduction to seed technology. London, Leonard Hill, 1979. 252p.

ZIMMERMAN, D.C. \& FICK, G.N. Fatty acid composition of sunflower (Helianthus annuus L.) oil as influenced by seed position. Journal of the American Oil Chemists Society, 50:273-275, 1973.

\& ZIMMER, D.E. Influence of harvest date and freezing on sunflower seed germination. Crop Science, 18:479-481, 1978. 